\title{
The Use of Smartphone-Based Triage to Reduce the Rate of Outpatient Error Registration: Cross-Sectional Study
}

\author{
Wanhua Xie ${ }^{1}, \mathrm{PhD}$; Xiaojun $\mathrm{Cao}^{2}$, MD; Hongwei Dong ${ }^{3}$, MD; Yu Liu ${ }^{1}$, BSN \\ ${ }^{1}$ Outpatient Department, Guangzhou Women and Children's Medical Center, Guangzhou Medical University, Guangzhou, China \\ ${ }^{2}$ Department of Science, Education and Data Management, Guangzhou Women and Children's Medical Center, Guangzhou Medical University, \\ Guangzhou, China \\ ${ }^{3}$ Hospital Office, Guangzhou Women and Children's Medical Center, Guangzhou Medical University, Guangzhou, China
}

\section{Corresponding Author:}

Wanhua Xie, PhD

Outpatient Department

Guangzhou Women and Children's Medical Center

Guangzhou Medical University

No 9 Jinhui Road

Tianhe District

Guangzhou, 510623

China

Phone: 8613725370379

Email: xiewanhua1@126.com

\section{Abstract}

Background: In many clinics, patients now have the option to make Web-based appointments but doing so according to their own judgment may lead to wrong registration and delayed medical services. We hypothesized that smartphone-based triage in outpatient services is superior to Web-based self-appointment registration guided by the medical staff.

Objective: This study aimed to investigate smartphone-based triage in outpatient services compared with Web-based self-appointment registration and to provide a reference for improving outpatient care under appointment registration.

Methods: The following parameters in Guangzhou Women and Children's Medical Center were analyzed: wrong registration rate, the degree of patient satisfaction, outpatient visits 6 months before and after smartphone-based triage, queries after smartphone-based triage, number of successful registrations, inquiry content, and top 10 recommended diseases and top 10 recommended departments after queries.

Results: Smartphone-based triage showed significant effects on average daily queries, which accounted for $16.15 \%(1956 / 12,112)$ to $29.46 \%(3643 / 12,366)$ of daily outpatient visits. The average daily successful registration after queries accounted for $56.14 \%$ $(1101 / 1961)$ to $60.92 \%(1437 / 2359)$ of daily queries and $9.33 \%(1130 / 12,112)$ to $16.83 \%(2081 / 12,366)$ of daily outpatient visits. The wrong registration rate after smartphone-based triage was reduced from $0.68 \%(12,810 / 1,895,829)$ to $0.12 \%(2379 / 2,017,921)$ $(P<.001)$, and the degree of patient satisfaction was improved. Monthly outpatient visits were increased by $0.98 \%(3192 / 325,710)$ to $13.09 \%(42,939 / 328,032)$ compared with the same period the preceding year $(P=.02)$.

Conclusions: Smartphone-based triage significantly reduces the wrong registration rate caused by patient Web-based appointment registration and improves the degree of patient satisfaction. Thus, it is worth promoting.

(JMIR Mhealth Uhealth 2019;7(11):e15313) doi: 10.2196/15313

\section{KEYWORDS}

smartphone; triage; outpatients; personal satisfaction

\section{Introduction}

\section{Background}

Medical systems worldwide face clinical, administrative, regulatory, and financial strains that require them to increase performance while reducing costs [1,2]. Hospitals often have a limited number of support staff responsible for patient registration and for taking medical history [3]. Registration by medical staff can create a bottleneck that increases waiting time and, thus, the likelihood of registration errors [4-6]. 
The National Health and Family Planning Commission of the People's Republic of China issued the Action Plan for Further Improving Medical Care Services in 2015, requiring appointment rates in tertiary hospitals to be at least $50 \%$ by the end of 2017 [7]. Therefore, hospitals began to implement appointment systems, and some of them implemented full appointment systems for nonemergency registration. The appointment systems alleviate the difficulty of temporary registration to a certain extent but may lead to wrong registration because of the limited medical knowledge of the patients. Song et al [8] reported that since the implementation of the full appointment system for nonemergency pediatric patients, the wrong registration rates by self-appointment and complaints from the children's families cannot be neglected and that the most important problem faced by the patients is the selection of the correct department [8]. This is further complicated by increasingly subdivided departments [9]. Xuezhen et al [10] reported that the loss of time and money caused by wrong registration directly leads to patient dissatisfaction with hospital visits.

Wrong registration not only wastes the time of the patients but may also lead to disease aggravation and delayed treatment. Lewis et al [11] proposed an effective clinical decision support tool to perform prehospital diagnosis and triage of ruptured aortic aneurysms accurately. Adapting such algorithms into smartphone apps that are used to make appointment registration could help decrease the error rates. It is feasible to use smartphone apps to report a dental emergency [12] and burns [13]. Previous studies mainly reported the use of smartphones for emergency triage and referral for some diseases [14-16], but the added value of using smartphone-based triage for regular appointments remains undefined. The most concerning aspect of adequate appointment registration is that the parents' level of information regarding their child's illness is limited [17]. Mobile health is a promising app for appointment registration [14]. WhatsApp (WhatsApp Inc) helps reduce unnecessary referrals and outpatient visits [15]. Smartphone-based pulse oximetry has been used to evaluate pediatric patients without hypoxia [16]. Reduction in waiting time from referral to first visit for community outpatient services might contribute to better health outcomes [18]. Therefore, investigating smartphone-based triage is critical in the modern era where the smartphone is becoming a central actor in everyday life.

In many clinics in China, the patients now have the option to make Web-based appointments, but doing so according to their own judgment may lead to wrong registration and delayed medical services. On the basis of the above, we hypothesized that smartphone-based triage in outpatient services is superior to Web-based self-appointment registration guided by the medical staff.

\section{Objectives}

Therefore, this study aimed to investigate the effect of smartphone-based triage on outpatient visits compared with
Web-based self-appointment registration, the rate of wrong registration made by the patients, the degree of patient satisfaction, and the effects on outpatient visits. This study provides a reference for improving outpatient appointment registration.

\section{Methods}

\section{Study Design and Subjects}

This was a cross-sectional study of patients who made appointments with the outpatient department of Guangzhou Women and Children's Medical Center between April 2018 and March 2019. This medical center is one of the hospitals that implemented a full appointment system for nonemergency appointment registration. There are more than 10,000 outpatient visits daily, and smartphone appointments among these outpatient visits accounted for a total of $77.15 \%(8692 / 11,266)$.

The inclusion criteria were that the participant (1) had records available during the study period in the hospital information system, (2) used a smartphone to book the appointment, and (3) had good communication skills and consented to participate. The exclusion criteria included (1) incomplete registration or appointment data or (2) multiple visits during the study period.

\section{Smartphone App}

Our hospital and Shenzhen Tencent Technology jointly developed and implemented smartphone-based triage based on symptoms recorded since October 2018. At the time of appointment registration, the option of selecting basic symptoms was added. Patients or family members can select symptoms based on disease conditions, which then accordingly guide them in selecting the adequate departments and doctors to visit. The best department can be selected according to different symptoms in the registration symptom page. In addition, the best route guidance can be provided based on precise, intelligent navigation within the hospital.

\section{Patient Grouping}

The patients recruited from April to September 2018 made Web-based appointment registration without the smartphone system, whereas from October 2018 to March 2019, outpatients started using the smartphone app for Web-based appointments.

\section{Indexing Process for Smartphone Self-Appointment System}

Disease indexing was performed by the patients. If the patient had a confirmed disease, the app immediately directed the patient to the appropriate department (Figure 1; Multimedia Appendix 1 shows screenshots of the app). If there was no confirmed diagnosis, the app asked a series of questions based on symptoms, discomfort, and terminology and then suggested the suitable departments to the patients. The app is completely automated. 
Figure 1. Self-appointment symptom index chart.

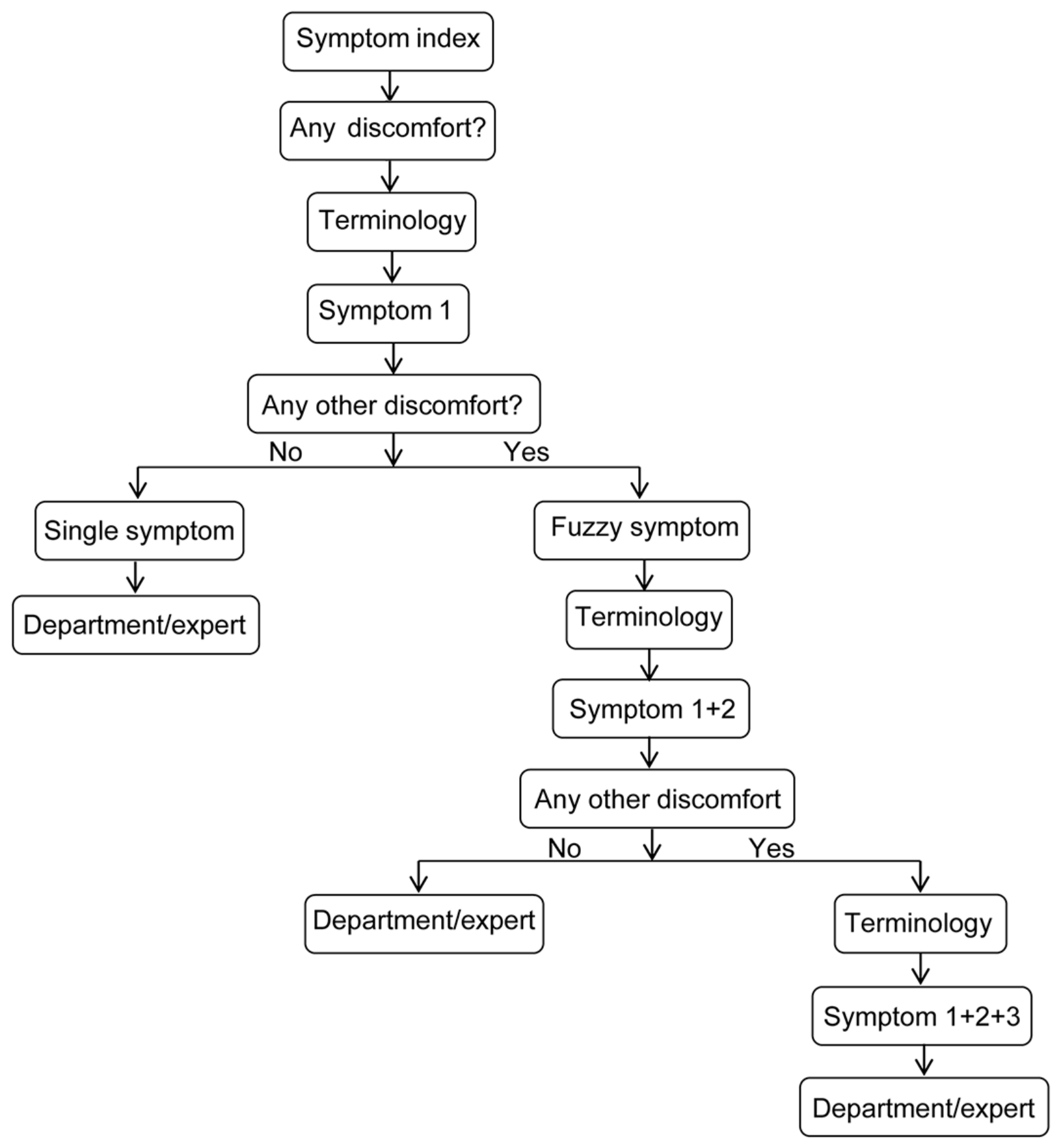

\section{Data Collection}

Smartphone-based triage had storage and memory functions. The medical staff could directly obtain the content from the background system and retrieve outpatient visits from the hospital operation and decision support system (business intelligence system). The degree of satisfaction regarding the accuracy of smartphone-based triage was extracted from the degree of satisfaction survey, which spanned the period from 6 months before smartphone-based triage to 6 months thereafter.

Patients in each department of Guangzhou Women and Children's Medical Center were enrolled. Random sampling was performed for selection, and assessment was carried out by 55 investigators who underwent unified training. The degree of satisfaction survey was performed on site at the hospital. According to the sample size, the survey of 1850 cases indicated that the interviewees were representative. General satisfaction was the first-level indicator. In addition, there were 6 second-level indicators, including general impression, service attitude, service quality, hospital environment, price perception, and medical ethics. Furthermore, 31 third-level indicators were assessed (Multimedia Appendix 2). The responses to third-level indicators were categorized using a 5-point Likert scale. The answers were coded from 1 to 5: 5-very satisfied, 4-satisfied, 3-neutral, 2-unsatisfied, and 1-very unsatisfied. The current internationally recognized method for calculating the satisfaction degree based on public opinion was adopted for evaluating each of the third-level indicators [19,20]: 100, very satisfied; 80, 
quite satisfied; 60, neutral; 40, dissatisfied; and 20, verydissatisfied. Unclear was assigned for missing values, which were excluded from the final analysis. A single indicator was calculated based on weighted calculation: degree of satisfaction $=$ proportion of very satisfied $\times 100+$ proportion of relatively satisfied $\times 80+$ proportion of generally satisfied $\times 60+$ proportion of not satisfied $\times 40+$ proportion of very dissatisfied $\times 20$. The overall degree of satisfaction was calculated by weighing each indicator score $[19,20]$. General satisfaction was calculated by summing the scores of all second-level indicators after multiplying them by their corresponding weights: general impression (5\%), service attitude (15\%), service quality (20\%), hospital environment (10\%), price perception (20\%), and medical ethics $(30 \%)$ [19,20].

\section{Statistical Analysis}

SPSS 23.0 (IBM) was used for data analysis. Queries and outpatient visits of smartphone-based triage were expressed as frequencies. The proportion of queries and inquiry content was expressed as a percentage. A comparison of wrong registration and the degree of satisfaction was analyzed by the Student $t$ test. $P<.05$ was considered statistically significant.

\section{Ethical Considerations}

The ethics committee of Guangzhou Women and Children's Medical Center (approval number SFE-KL-28201) approved this study. Patients or their guardians provided signed informed consent.

\section{Results}

\section{Effect of Smartphone-Based Triage}

The average daily numbers of smartphone-based triage used for the 6 consecutive months were 2359, 1917, 1956, 1961, 3067, and 3643 , accounting for $22.23 \%(2359 / 10,610), 16.37 \%$ (1917/11,717), 16.15\% (1956/12,112), 23.20\% (1961/8453), $26.09 \%(3067 / 11,754)$, and $29.46 \%(3643 / 12,366)$ of all outpatient visits, respectively. The average number of daily queries for the whole study period was 2730 , which was equal to the workload of at least nine experienced precheck triage nurses and hospital guiding staff. The numbers of successful daily registrations after smartphone-based triage for the 6 consecutive months were $1437,1101,1130,1101,1736$, and 2081, accounting for $60.92 \%$ (1437/2359), 57.43\% (1101/1917), $57.77 \%$ (1130/1956), 56.14\% (1101/1961), 56.60\% (1736/3067), and $57.12 \%(2081 / 3643)$ of all queries, respectively, and $13.54 \%$ (1437/10,610), 9.40\% (1101/11,717), 9.33\% (1130/12,112), $13.02 \%(1101 / 8453), 14.77 \%(1736 / 11,754)$, and $16.83 \%$ (2081/12,366), respectively, of all daily outpatient visits in the respective months (Table 1).

Table 1. Queries of smartphone-based triage, successful registrations after query, and proportions of outpatient visits.

\begin{tabular}{llll}
\hline $\begin{array}{l}\text { Time } \\
\text { (months) }\end{array}$ & Daily outpatient visits & $\begin{array}{l}\text { Proportion of daily queries to outpatient } \\
\text { visits, } \mathrm{n}(\%)\end{array}$ & $\begin{array}{l}\text { Proportion of successful daily registrations after query to outpa- } \\
\text { tient visits, } \mathrm{n}(\%)\end{array}$ \\
\hline 1 & 10,610 & $2359(22.23)$ & $1437(13.54)$ \\
2 & 11,717 & $1917(16.37)$ & $1101(9.40)$ \\
3 & 12,112 & $1956(16.15)$ & $1130(9.33)$ \\
4 & 8453 & $1961(23.20)$ & $1101(13.02)$ \\
5 & 11,754 & $3067(26.09)$ & $1736(14.77)$ \\
6 & 12,366 & $3643(29.46)$ & $2081(16.83)$ \\
\hline
\end{tabular}

\section{Reduction in Wrong Registrations}

The number of wrong registrations during the 6 months before smartphone-based triage was 12,810 , accounting for $0.68 \%$ of all outpatient visits $(1,895,829)$, that is, 2135 (SD 37) wrong registrations recorded monthly. This number was significantly reduced to 2379 after smartphone-based triage, accounting for $0.12 \%$ of all outpatient visits $(2,017,921)$, that is, 396 (SD 17) wrong registrations recorded monthly $(95 \%$ CI 1701.362-1771.68; $P<.001)$.

\section{Improved Degree of Satisfaction of the Outpatients}

A total of 7400 questionnaires were released and 7188 were collected, indicating an effective recovery rate of $97.14 \%$. The questionnaire survey data are shown in Table 2. A comparison of the first and second quarters after smartphone-based triage with pre-smartphone-based triage showed a significant improvement in the degree of patient satisfaction $(P<.001$; Table 3). 
Table 2. Basic information of the degree of patient satisfaction before and after smartphone-based triage.

\begin{tabular}{|c|c|c|c|c|}
\hline Item and condition & $\begin{array}{l}\text { Second quarter before } \\
\text { triage }\end{array}$ & First quarter before triage & First quarter after triage & Second quarter after triage \\
\hline \multicolumn{5}{|l|}{ Valid questionnaires } \\
\hline Copies & 1832 & 1838 & 1802 & 1716 \\
\hline \multicolumn{5}{|l|}{ Sex, n (\%) } \\
\hline Female & $970(52.95)$ & $1112(60.50)$ & $1116(61.93)$ & $1065(62.06)$ \\
\hline Male & $862(47.05)$ & $726(39.50)$ & $686(38.07)$ & $651(37.94)$ \\
\hline \multicolumn{5}{|l|}{ Payment, n (\%) } \\
\hline Self-paying & $1280(69.87)$ & $1141(62.08)$ & $1168(64.82)$ & $1067(62.18)$ \\
\hline Medical insurance & $454(24.78)$ & $623(33.90)$ & $563(31.24)$ & $579(33.74)$ \\
\hline Public expense & $98(5.35)$ & $74(4.02)$ & $71(3.94)$ & $70(4.08)$ \\
\hline \multicolumn{5}{|l|}{ Residence, n (\%) } \\
\hline Local & $1290(70.41)$ & $1317(71.65)$ & $1300(72.14)$ & $1315(76.63)$ \\
\hline Other city in local province & $466(25.44)$ & $389(21.17)$ & $372(20.64)$ & $323(18.82)$ \\
\hline Other province & $76(4.15)$ & $132(7.18)$ & $130(7.22)$ & $784.55)$ \\
\hline \multicolumn{5}{|l|}{ Sample classification, $\mathbf{n}(\%)$} \\
\hline Patient himself & $336(18.34)$ & $443(24.10)$ & $527(29.25)$ & $501(29.20)$ \\
\hline Relatives and friends & $1496(81.66)$ & $1395(75.90)$ & $1275(70.75)$ & $1215(70.80)$ \\
\hline \multicolumn{5}{|l|}{ Educational level, n (\%) } \\
\hline Below junior middle school & $243(13.26)$ & $296(16.10)$ & $276(15.32)$ & $229(13.34)$ \\
\hline $\begin{array}{l}\text { High school or technical secondary } \\
\text { school }\end{array}$ & $432(23.58)$ & $432(23.50)$ & $421(23.36)$ & $340(19.81)$ \\
\hline Junior college or undergraduate & $1073(58.57)$ & $1028(55.93)$ & $1022(56.71)$ & $1062(61.89)$ \\
\hline Master degree or above & $84(4.59)$ & $82(4.47)$ & $83(4.61)$ & $85(4.96)$ \\
\hline
\end{tabular}

Table 3. Comparison of satisfaction level before and after smartphone-based triage.

\begin{tabular}{lllll}
\hline Time & After smartphone-based triage, mean (SD) & Before smartphone-based triage, mean (SD) & $P$ value & Odds Ratio (95\% CI) \\
\hline First quarter & $87.05(3.49)$ & $85.77(3.71)$ & $<.001$ & $1.059(0.482-2.327)$ \\
Second quarter & $87.60(3.32)$ & $85.27(3.26)$ & $<.001$ & $0.773(0.342-1.747)$ \\
\hline
\end{tabular}

\section{Degree of Satisfaction Regarding the Accuracy of Smartphone-Based Triage}

The survey conducted in 1850 patients about the degree of satisfaction regarding the accuracy of smartphone-based triage showed that 1601 patients were satisfied $(88.68 \%), 144$ were neutral $(7.98 \%), 60$ were dissatisfied $(3.34 \%)$, and 45 were missing.

\section{Proportions of Inquiries in the Content of Smartphone-Based Triage}

For patients inputting their diseases and symptoms in smartphone-based triage, those waiting for disease judgment accounted for 48,596 (57.68\%), those looking for a doctor accounted for $14,184(16.84 \%)$, those in the inquiry process accounted for $7260(8.62 \%)$, those with other questions accounted for $6712(7.97 \%)$, those inquiring for examination accounted for 3994 (4.74\%), and those looking for the department accounted for 3502 (4.15\%).

\section{Top 10 Queries of Disease Recommendation}

The top 10 queries were associated with unspecified-site acute upper respiratory tract infection; other infectious diseases and unspecified etiologies, gastroenteritis, and colitis, other and unclear pyrexia, acute nasopharyngitis cold, influenza without labeled virus, cough, bronchitis unspecified as acute or chronic, pneumonia with unspecified pathogen, hand-foot-and-mouth disease, chronic disease of tonsils and adenoids.

\section{Top 10 Queries of Department Recommendation}

The top 10 queries based on department recommendations were associated with the deputy director of outpatient internal medicine, attending internal medicine department, attending respiratory outpatient, attending auricle deformity department, chief of pediatric respiratory department, attending otolaryngology department, chief of otolaryngology department, attending dermatology department, deputy director of dermatology department and attending outpatient department of gastroenterology. 


\section{Changes in Outpatient Visits Before and After Smartphone-Based Triage}

The outpatient visits were increased by $0.98 \%$ (3192/325,710) to $13.09 \%(42,939 / 328,032)$ compared with the same period last year, and monthly outpatient visits after 6 months of smartphone-based triage were 328,902, 351,518, 375,458, $236,690,364,382$, and 370,971. Compared with the outpatient visits in the same period last year, the outpatient visits were increased by $0.98 \%(3192 / 325,710), 4.40 \%(14,815 / 336,703)$, $9.22 \% \quad(31,695 / 343,763), \quad 5.22 \% \quad(11,742 / 224,948), 8.23 \%$ $(27,708 / 336,674)$, and $13.09 \% \quad(42,939 / 328,032)$, after smartphone-based triage (95\% CI 6525.769-41,544.565; $P=.02$ ).

\section{Discussion}

\section{Principal Findings}

Human-based patient registration requires money, time, and human resources and often represents a bottleneck for patient registration [1-6]. In China, where the health care system is based on specialists rather than generalists, the patients now have the option to make Web-based appointments, but doing so according to their own judgment may lead to wrong registration and delayed medical services. This study investigated the effect of implementing smartphone-based triage in the outpatient department compared with Web-based self-appointment registration, smartphone-based triage queries, rate of successful registration after query, rate of wrong registration, degree of patient satisfaction, and the top 10 recommended diseases and departments. The results indicated that smartphone-based triage has significant effects on appointment registration and is well accepted by the patients and family members, reduces wrong registration caused by patient Web-based appointment registration, and improves the degree of patient satisfaction.

This showed that patients could use smartphones to consult the doctor anytime from anywhere to be guided to the right department, thereby optimizing the visit process, reducing the wrong registration rate, and improving the degree of patient satisfaction. De Bruin et al [21] confirmed that a smartphone-based triage app was well accepted by the patients.

Previous studies reported improved effectiveness of patient registration. Nogueira et al [22] proposed the FAST-ED app for improving smartphone-based triage in acute ischemic stroke patients, and Uthoff et al [23] reported the use of smartphones in the early discovery of oral cancer lesions. Tayfur and Afacan [24] showed that the patients could perform a smartphone-based triage evaluation before seeing a doctor. Verzantvoort et al [25] stated that smartphone-based triage plays an important role in patients who are consulting doctors. Tian et al [26] used a simulation model to evaluate a mobile-based system for supporting emergency evacuation decision making. Gupta et al [27] reported technicians using a store-and-forward telemedicine device to screen for ear problems. Astarcioglu et al [28], Borve et al [29], Dahlen Gyllencreutz et al [30], and Urner et al [31] investigated the use of smartphones in skin cancer referral, time-to-reperfusion in ST-segment elevation myocardial infarction undergoing inter-hospital transfers, teledermoscopy images acquired in primary health care and hospital settings, and accuracy in triage imaging of human papillomavirus-positive women, respectively. All these studies showed that the use of smartphone-based triage improved the wrong registration rates and patient satisfaction in specific patient populations. This study is supported by those studies and provides a higher degree of generalization as all women and pediatric patients were included, irrespective of their disease, and the department consulted. Nevertheless, those previous studies did not report how many outpatients were willing to participate in the clinical study. In contrast, this study demonstrated that queries associated with smartphone-based triage were significant, and the triage was well accepted by patients.

\section{Strengths and Limitations}

A major advantage of the system used in this study was that no special smartphone requirement was set, and registration and smartphone-based triage could be followed after the patient had logged into the official WeChat account. Resources should be effectively allocated while using information systems [21]. In this study, smartphone-based triage took advantage of information technology to replace most of the work of routine field manual preinspection and triage by clinical service staff, effectively allocating resources. Not all patients used the smartphone app for appointment registration, but many of those who used the app did not require any assistance for the selection of the right department. This system could save time and energy of the support staff and effectively improve the utility of the precious medical resources.

Our hospital is specialized in pediatrics and woman health care; hence, more than $70 \%$ of outpatient visits were in the pediatric department. Nevertheless, the study showed that after the implementation of smartphone-based triage, the total outpatient visits increased compared with the previous year. The exact reasons for this increase remain unknown and deserve further investigation.

This study has limitations. The study site was limited to 1 hospital, and the collected data and indicators were limited. There was no randomization, and there could be a temporal bias. Multicenter trials with several indicators are required to confirm the findings. In addition, the app assessed in this study was specific to countries with a health system centered on hospital consultations by specialists, which is not the case in several other countries (eg, in Europe and America), where the patients consult a general practitioner who manages almost all diseases and refers to the proper specialists when needed. The questionnaire was not validated. Nevertheless, the 5-point Likert scale was used in this study. Finally, as the use of technology is often dependent upon age, financial resources, and education, future studies should examine the influence of those factors to optimize the use of the smartphone app for various populations of patients.

\section{Conclusions}

In conclusion, smartphone-based triage significantly improves the rate of wrong patients' Web-based appointment registration and improves the degree of patient satisfaction. It allocates 
expert resources more effectively, saving manpower for prediagnosis, triage, and patient guiding. Thus, such a smartphone approach is worth promoting. Future studies could examine its use by medical staff for inpatient management and transfer among departments. It could also be examined in general practitioners-centered settings.

\section{Acknowledgments}

The authors are grateful for information collected by the medical staff in the outpatient department and Guangdong Situation Research Center. The study was funded by Guangzhou Science and Technology Plan Project (201806020047).

\section{Conflicts of Interest}

None declared.

\section{Multimedia Appendix 1}

Screenshots of smartphone-based triage.

[PNG File, 240 KB-Multimedia Appendix 1]

\section{Multimedia Appendix 2}

Satisfaction questionnaire.

[DOC File, 85 KB-Multimedia Appendix 2]

\section{References}

1. Young RA, Burge SK, Kumar KA, Wilson JM, Ortiz DF. A time-motion study of primary care physicians' work in the electronic health record era. Fam Med 2018 Feb;50(2):91-99 [FREE Full text] [doi: 10.22454/FamMed.2018.184803] [Medline: 29432623]

2. Sinsky C, Colligan L, Li L, Prgomet M, Reynolds S, Goeders L, et al. Allocation of physician time in ambulatory practice: a time and motion study in 4 specialties. Ann Intern Med 2016 Dec 6;165(11):753-760. [doi: 10.7326/M16-0961] [Medline: 27595430]

3. Jadczyk T, Kiwic O, Khandwalla RM, Grabowski K, Rudawski S, Magaczewski P, et al. Feasibility of a voice-enabled automated platform for medical data collection: CardioCube. Int J Med Inform 2019 Sep;129:388-393. [doi: 10.1016/j.ijmedinf.2019.07.001] [Medline: 31445282]

4. Knight V, Guy RJ, Handan W, Lu H, McNulty A. It is more efficient to type: innovative self-registration and appointment self-arrival system improves the patient reception process. Sex Transm Dis 2014 Jun;41(6):392-394. [doi: 10.1097/OLQ.0000000000000136] [Medline: 24825337]

5. Li LX, Benton WC, Leong G. The impact of strategic operations management decisions on community hospital performance. J Oper Manag 2002;20(4):389-408. [doi: 10.1016/s0272-6963(02)00002-5]

6. Cao W, Wan Y, Tu H, Shang F, Liu D, Tan Z, et al. A web-based appointment system to reduce waiting for outpatients: a retrospective study. BMC Health Serv Res 2011 Nov 22;11:318 [FREE Full text] [doi: 10.1186/1472-6963-11-318] [Medline: 22108389]

7. State Health and Family Planning Commission of the People's Republic of China. 2015. URL: http://www.nhc.gov.cn/ [accessed 2019-11-04]

8. Song Z, Li Z, Sun L, Yan C, Li X. [Status quo analysis on reservation registration based on patient complaint in a children hospital]. Chin Hosp 2017;21:58-59 [FREE Full text]

9. Zhi W, Ran X, Yanfeng J. [The Research of Self-help Registration System Based on Information Index]. Chin Figit Med 2014;9:26-28. [doi: 10.3969/j.issn.1673-7571.2014.10.007]

10. Xuezhen X, Jianping C, Yueying G. [Qualitative research on experience and psychological experience of outpatients with wrong registration]. Nurs Rehab J 2015;14:211-213. [doi: 10.3969/j.issn.1671-9875.2015.03.003]

11. Lewis TL, Fothergill RT, Aneurysm-FILTR Study Group, Karthikesalingam A. Ambulance smartphone tool for field triage of ruptured aortic aneurysms (FILTR): study protocol for a prospective observational validation of diagnostic accuracy. BMJ Open 2016 Oct 24;6(10):e011308 [FREE Full text] [doi: 10.1136/bmjopen-2016-011308] [Medline: 27797986]

12. Stein CD, Xiao X, Levine S, Schleyer TK, Hochheiser H, Thyvalikakath TP. A prototype mobile application for triaging dental emergencies. J Am Dent Assoc 2016 Oct;147(10):782-91.e1 [FREE Full text] [doi: 10.1016/j.adaj.2016.03.021] [Medline: 27206728]

13. den Hollander D, Mars M. Smart phones make smart referrals: The use of mobile phone technology in burn care - a retrospective case series. Burns 2017 Feb;43(1):190-194. [doi: 10.1016/j.burns.2016.07.015] [Medline: 27575675]

14. Morse SS, Murugiah MK, Soh YC, Wong TW, Ming LC. Mobile health applications for pediatric care: review and comparison. Ther Innov Regul Sci 2018 May;52(3):383-391. [doi: 10.1177/2168479017725557] [Medline: 29714538] 
15. Martinez R, Rogers AD, Numanoglu A, Rode H. The value of WhatsApp communication in paediatric burn care. Burns 2018 Jun;44(4):947-955. [doi: 10.1016/j.burns.2017.11.005] [Medline: 29395403]

16. Tomlinson S, Behrmann S, Cranford J, Louie M, Hashikawa A. Accuracy of smartphone-based pulse oximetry compared with hospital-grade pulse oximetry in healthy children. Telemed J E Health 2018 Jul;24(7):527-535. [doi: 10.1089/tmj.2017.0166] [Medline: 29215972]

17. Pidgeon TE, Blore CD, Webb Y, Horton J, Evans M. A patient information leaflet reduces parental anxiety before their child's first craniofacial multidisciplinary outpatient appointment. J Craniofac Surg 2017 Oct;28(7):1772-1776. [doi: 10.1097/SCS.0000000000003955] [Medline: 28891904]

18. Lewis AK, Harding KE, Snowdon DA, Taylor NF. Reducing wait time from referral to first visit for community outpatient services may contribute to better health outcomes: a systematic review. BMC Health Serv Res 2018 Nov 20;18(1):869 [FREE Full text] [doi: 10.1186/s12913-018-3669-6] [Medline: 30458761]

19. Randolph LA, Walker CK, Nguyen AT, Zachariah SR. Impact of pharmacist interventions on cost avoidance in an ambulatory cancer center. J Oncol Pharm Pract 2018 Jan;24(1):3-8. [doi: 10.1177/1078155216671189] [Medline: 27682600]

20. Keshvani N, Hon M, Gupta A, Brown TJ, Roy L, Marley E, et al. Reducing hospitalizations: institution of outpatient infusional epoch-based chemotherapy at a safety net hospital. J Oncol Pract 2019 Aug;15(8):e644-e651. [doi: 10.1200/JOP.18.00738] [Medline: 31206340]

21. de Bruin JS, Schuh C, Seeling W, Luger E, Gall M, Hütterer E, et al. Assessing the feasibility of a mobile health-supported clinical decision support system for nutritional triage in oncology outpatients using Arden Syntax. Artif Intell Med 2018 Nov;92:34-42. [doi: 10.1016/j.artmed.2015.10.001] [Medline: 26563776]

22. Nogueira RG, Silva GS, Lima FO, Yeh Y, Fleming C, Branco D, et al. The FAST-ED app: a smartphone platform for the Field Triage of patients with stroke. Stroke 2017 May;48(5):1278-1284. [doi: 10.1161/STROKEAHA.116.016026] [Medline: 28411260]

23. Uthoff RD, Song B, Sunny S, Patrick S, Suresh A, Kolur T, et al. Point-of-care, smartphone-based, dual-modality, dual-view, oral cancer screening device with neural network classification for low-resource communities. PLoS One 2018;13(12):e0207493 [FREE Full text] [doi: 10.1371/journal.pone.0207493] [Medline: 30517120]

24. Tayfur I, Afacan MA. Reliability of smartphone measurements of vital parameters: A prospective study using a reference method. Am J Emerg Med 2019 Aug;37(8):1527-1530. [doi: 10.1016/j.ajem.2019.03.021] [Medline: 30904343]

25. Verzantvoort NC, Teunis T, Verheij TJ, van der Velden AW. Self-triage for acute primary care via a smartphone application: Practical, safe and efficient? PLoS One 2018;13(6):e0199284 [FREE Full text] [doi: 10.1371/journal.pone.0199284] [Medline: 29944708]

26. Tian Y, Zhou T, Yao Q, Zhang M, Li J. Use of an agent-based simulation model to evaluate a mobile-based system for supporting emergency evacuation decision making. J Med Syst 2014 Dec;38(12):149. [doi: 10.1007/s10916-014-0149-3] [Medline: 25354665]

27. Gupta N, Chawla N, Gupta D, Dhawan N, Janaki VR. Community triage of otology patients using a store-and-forward telemedicine device: A feasibility study. Ear Nose Throat J 2017 Jul;96(7):246-249. [Medline: 28719707]

28. Astarcioglu MA, Sen T, Kilit C, Durmus HI, Gozubuyuk G, Kalcik M, et al. Time-to-reperfusion in STEMI undergoing interhospital transfer using smartphone and WhatsApp messenger. Am J Emerg Med 2015 Oct;33(10):1382-1384. [doi: 10.1016/j.ajem.2015.07.029] [Medline: 26299691]

29. Börve A, Gyllencreutz JD, Terstappen K, Backman EJ, Aldenbratt A, Danielsson M, et al. Smartphone teledermoscopy referrals: a novel process for improved triage of skin cancer patients. Acta Derm Venereol 2015 Feb;95(2):186-190 [FREE Full text] [doi: 10.2340/00015555-1906] [Medline: 24923283]

30. Gyllencreutz JD, Backman EJ, Terstappen K, Paoli J. Teledermoscopy images acquired in primary health care and hospital settings - a comparative study of image quality. J Eur Acad Dermatol Venereol 2018 Jun;32(6):1038-1043. [doi: 10.1111/jdv.14565] [Medline: 28850732]

31. Urner E, Delavy M, Catarino R, Viviano M, Meyer-Hamme U, Benski A, et al. A smartphone-based approach for triage of human papillomavirus-positive Sub-Saharan African women: a prospective study. JMIR Mhealth Uhealth 2017 May 29;5(5):e72 [FREE Full text] [doi: 10.2196/mhealth.6697] [Medline: 28554879]

Edited by G Eysenbach; submitted 01.07.19; peer-reviewed by F Kaliyadan, S Badawy, JR Bautista, T Clavier; comments to author 21.08.19; revised version received 16.10.19; accepted 17.10.19; published 11.11.19

Please cite as:

Xie W, Cao X, Dong H, Liu Y

The Use of Smartphone-Based Triage to Reduce the Rate of Outpatient Error Registration: Cross-Sectional Study

JMIR Mhealth Uhealth 2019;7(11):e15313

URL: http://mhealth.jmir.org/2019/11/e15313/

doi: $\underline{10.2196 / 15313}$

PMID: $\underline{31710300}$ 
(C) Wanhua Xie, Xiaojun Cao, Hongwei Dong, Yu Liu. Originally published in JMIR Mhealth and Uhealth (http://mhealth.jmir.org), 11.11.2019. This is an open-access article distributed under the terms of the Creative Commons Attribution License (https://creativecommons.org/licenses/by/4.0/), which permits unrestricted use, distribution, and reproduction in any medium, provided the original work, first published in JMIR mhealth and uhealth, is properly cited. The complete bibliographic information, a link to the original publication on http://mhealth.jmir.org/, as well as this copyright and license information must be included. 